\title{
Carbon Dioxide in Lake Nyos, Cameroon, Estimated Quantitatively From Sound Speed Measurements
}

\author{
Bertram Boehrer ${ }^{1 *}$, Kazuto Saiki ${ }^{2}$, Takeshi Ohba $^{3}$, Greg Tanyileke ${ }^{4}$, Dmitri Rouwet $^{5}$ and \\ Minoru Kusakabe ${ }^{6}$
}

${ }^{1}$ Helmholtz-Centre for Environmental Research - UFZ, Magdeburg, Germany, ${ }^{2}$ Graduate School of Science, Osaka University, Osaka, Japan, ${ }^{3}$ School of Science, Tokai University, Hiratsuka, Japan, ${ }^{4}$ Institute for Geological and Mining Res. (IRGM), Yaounde, Cameroon, ${ }^{5}$ Istituto Nazionale di Geofisica e Vulcanologia, Sezione di Bologna, Bologna, Italy, ${ }^{6}$ University of Toyama, Toyama, Japan

OPEN ACCESS

Edited by:

John Stix,

McGill University, Canada

Reviewed by:

Pingping Luo,

Chang'an University, China Ahmed Kenawy,

Mansoura University, Egypt

${ }^{*}$ Correspondence:

Bertram Boehrer

Bertram.Boehrer@ufz.de

Specialty section:

This article was submitted to

Volcanology,

a section of the journa

Frontiers in Earth Science

Received: 04 March 2021 Accepted: 01 July 2021

Published: 28 July 2021

Citation:

Boehrer B, Saiki K, Ohba T,

Tanyileke $G$, Rouwet $D$ and Kusakabe M (2021) Carbon Dioxide in

Lake Nyos, Cameroon, Estimated

Quantitatively From Sound

Speed Measurements.

Front. Earth Sci. 9:645011.

doi: 10.3389/feart.2021.645011
Gases dissolved in the deep water of lakes can pose a hazard when extreme concentrations are reached. A sudden release of large amounts of gas can cost the lives of humans living in the neighbourhood, as happened at Lake Nyos in 1986. Since 2001, the gas risk at Lake Nyos has been mitigated by induced degassing, but the lake continues to be supplied by $\mathrm{CO}_{2}$, and a regular survey needs to be implemented to guarantee safe conditions. Frequent sampling of this remote lake requires an enormous effort, and many analytical techniques are very difficult to run at the lake site. In this contribution, we combined a commercially available sound speed sensor with a CTD (electrical conductivity, temperature, depth) probe to obtain an indirect but quantitative estimate of carbon dioxide concentrations with fine depth resolution (decimetre scale). Dissolved carbon dioxide increases sound speed but does not contribute to electrical conductivity. Hence the difference between measured and calculated (on the base of electrical conductivity, temperature and pressure) sound speed gives a quantitative indication of dissolved carbon dioxide. We infer the vertical distribution of dissolved $\mathrm{CO}_{2}$ and hence continue the survey of the progress of the intended degassing. In conclusion, we present an easy to implement method for very high $\mathrm{CO}_{2}$ concentrations in deep lakes, and we highly recommend the implementation of the sound speed-CTD probe combination at Lake Nyos and at other gas-laden volcanic lakes, as such an approach could safeguard the people living in the area with acceptable cost and effort for the operators. In this manner, alarming $\mathrm{CO}_{2}$ concentrations in deep parts of lakes can be detected in a timely fashion.

Keywords: gas, gas pressure, lake Nyos, limnic eruption, remediation, sound speed

\section{INTRODUCTION}

Extreme concentrations of dissolved gases in deep waters of lakes can pose a threat to the local population. Sudden limnic overturns can liberate large volumes of gas, which can asphyxiate humans and livestock, as happened at Lake Monoun in 1984 and at Lake Nyos in 1986 (Kling et al., 1987; Sigurdsson et al., 1987). More than 1700 humans perished in these natural disasters. Also at other places, extreme gas pressures have been detected and assessed for their danger to the local population (Lake Kivu: Lorke et al., 2004; Schmid et al., 2005; Guadiana Pit Lake: Sánchez España et al., 2014; 
Boehrer et al., 2016; Lake Vollert-Sued: Horn et al., 2017; Lago Monticchio Piccolo: Caracausi et al., 2009; Cabassi et al., 2013). All these lakes are meromictic, and accumulation of solutes in the deep water can occur over long periods (e.g., Boehrer et al., 2013; Boehrer et al., 2021). In some cases, artificial degassing is considered necessary to reduce risk around the lakes (Nyos, Monoun, Guadiana Pit Lake; Sánchez España et al., 2020).

Even after removal of the gas, some of the lakes still maintain their connection to the gas source, allowing for gas recharge, as seen in Lake Monoun (Kusakabe, 2017). Other lakes, such as Lago Albano, can be recharged with gas in a sudden manner by seismic activity (Chiodini et al., 2012; Rouwet et al., 2019; Rouwet et al., 2021; Rouwet, 2021). To avoid dangerous levels of gas accumulation, gas concentrations need to be surveyed regularly. Reliable measurements of high gas concentrations are difficult, as intensive efforts on Lake Kivu have shown (Boehrer et al., 2019; Bärenbold et al., 2020, and references therein). Especially in remote localities such as Lake Nyos, measurements with sophisticated equipment and complex procedures require an enormous logistical effort. Simple, portable equipment would be most practicable for such surveys. Sanemasa et al. (2017) provided measurements of sound speed which were affected by high concentrations of carbon dioxide; they indicated that sound speed measurements could be used to quantify carbon dioxide in Lake Nyos. Saiki et al. (2017) presented measurements of sound speed with a Minos X (AML Oceanographic) used for calibrating a multibeam sonar. They correlated measured $\mathrm{CO}_{2}$ concentrations with measured sound speeds, and demonstrated that such measurements are feasible and provide a good quantitative estimate of the carbon dioxide dissolved in the lake water.

In March 2016, 30 years after the disaster of the Nyos limnic eruption, a conference was held in Yaounde (Cameroon) to reflect upon the work so far that dealt with managing the danger of limnic eruptions at Lake Nyos and Lake Monoun. The goal was to understand the underlying volcanic connections and to examine lessons learnt from the Nyos and Monoun remediation efforts (Tanyileke et al., 2019). Artificial degassing had been induced beginning in 2001 when the first degassing tube went into operation. Degassing was enhanced in 2011 with two additional degassing tubes. The scientific meeting, the 9th Workshop of the International Association of Volcanology and Chemistry of the Earth's Interior (IAVCEI) Commission on Volcanic Lakes, was complemented by a short field campaign to document the situation in 2016, i.e., at a time when the forced degassing had removed most of the gas from the deep layer of Lake Nyos (Kusakabe, 2017; Kusakabe et al., 2019; Tanyileke et al., 2019; Halbwachs et al., 2020).

The aim of this study was the field deployment of commercially available equipment (i.e., a conductivity-densitydepth probe with a sound speed sensor) to yield a profile of dissolved inorganic carbon (DIC hereafter) concentrations based on the excess sound speed in comparison to calculated sound speed. The well studied Lake Nyos itself was arguably the best suited natural laboratory to develop and verify our approach. However, in addition to the studies by Saiki et al. (2017) and Sanemasa et al. (2017), we included conductivity in the

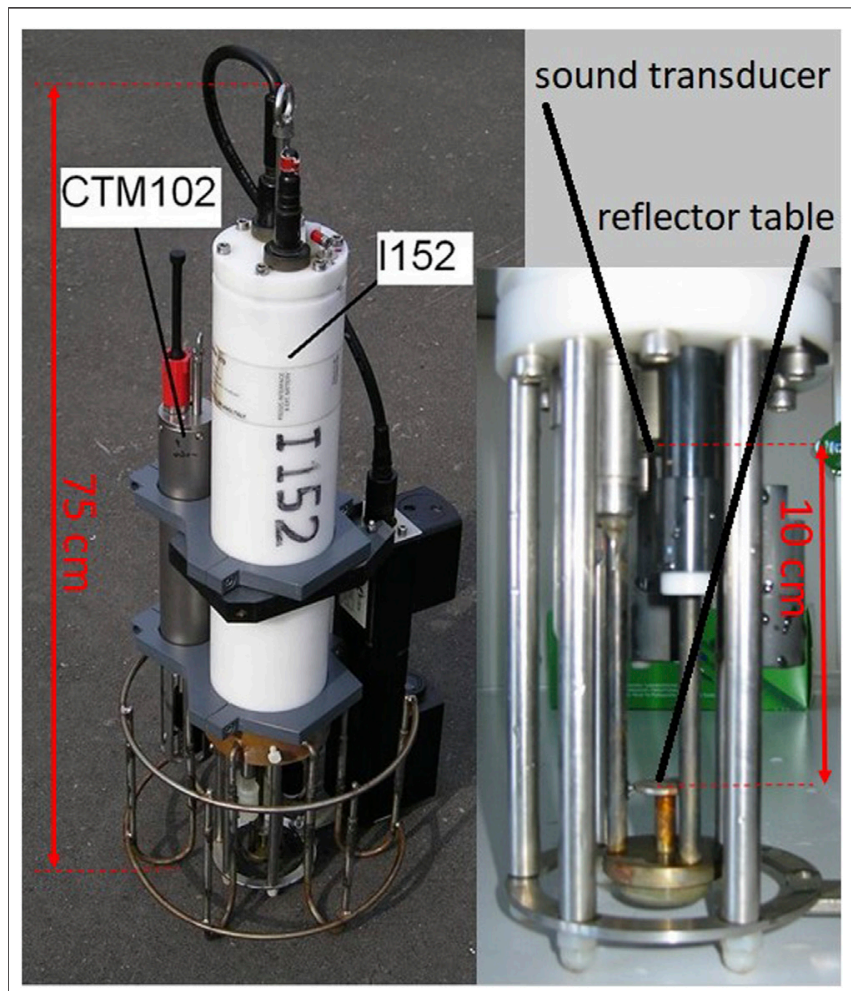

FIGURE 1 | The deployed multiparameter probe Idronaut Ocean Seven 316 "I152" with the VALEPORT sound speed sensor mounted together with a faster CTD probe "CTM102" (Sea and Sun Technology, Germany).

calculations and considerations of sound speed to correlate actual $\mathrm{CO}_{2}$ (instead of DIC) with sound speed. We present a $\mathrm{pH}$ and site independent (background salinity) approach; hence this method has the potential to be applied to other highly $\mathrm{CO}_{2}$ laden lakes.

\section{MEASUREMENTS}

Lake Nyos is located in the Cameroon Volcanic Line in the western part of Cameroon $\left(06^{\circ} 26^{\prime} \mathrm{N}, 10^{\circ} 17^{\prime} \mathrm{E}\right)$ at an altitude of $1,091 \mathrm{~m}$ asl. Its maximum depth reaches $210 \mathrm{~m}$ with a surface area of $1.58 \mathrm{~km}^{2}$ compared to the catchment area of about $8 \mathrm{~km}^{2}$ and a lake volume of $1.6 \times 10^{8} \mathrm{~m}^{3}$ (Tanyileke et al., 2019). The lake has been meromictic and is known for its high carbon dioxide concentrations in the deep water, which caused a limnic eruption in 1986 costing the lives of 1,746 people.

We took part in the Nyos field campaign in 2016. We lowered our custom-built oceanographic multiparameter probe by hand from the surface to the maximum depth on a rope to document the stratification of temperature and electrical conductivity (EC hereafter) at the time. The probe was also equipped with an oxygen sensor and a $\mathrm{pH}$ sensor. In addition, it carried a sound speed sensor for direct measurements. Both the probe ("i152", Ocean Seven 316, Idronaut, Italy) and the sound speed sensor (VALEPORT, United Kingdom) were commercially available, and the probe manufacturer customized the sound speed sensor 


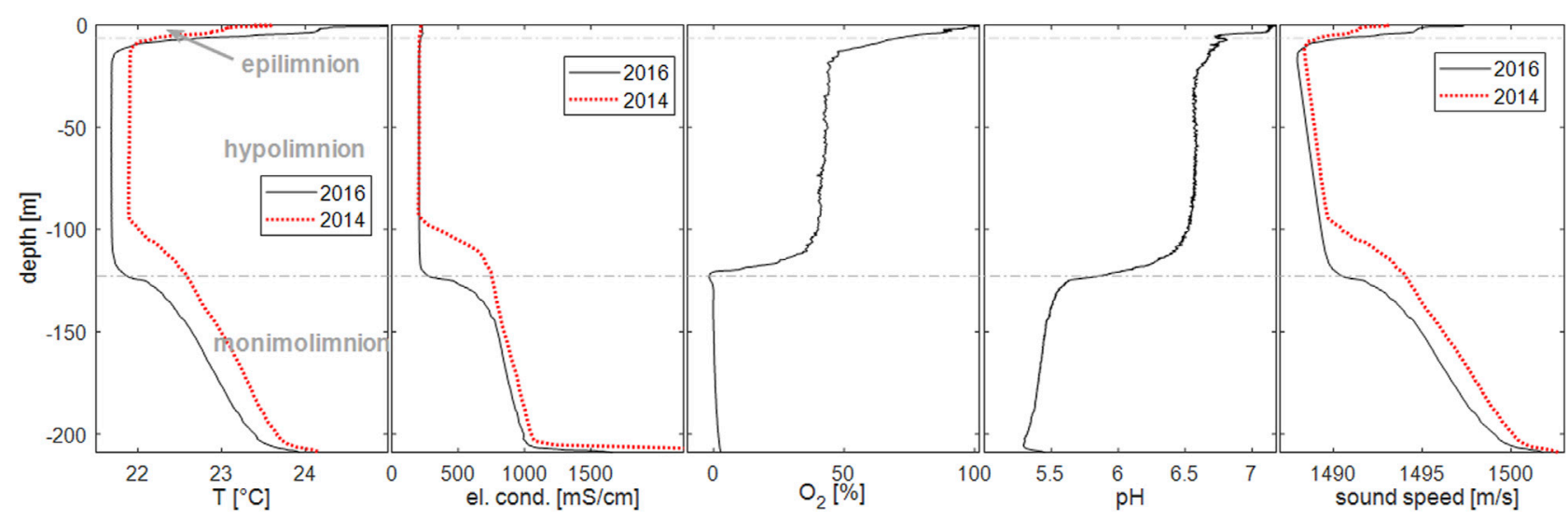

FIGURE 2|Profiles of temperature, electrical conductivity at $25^{\circ} \mathrm{C}$, oxygen saturation (calibrated on local conditions), pH and sound speed measured in Lake Nyos on 2016-03-19 in comparison with measurements in 2014 [2014 data from Saiki et al. (2017): broken red lines]. The broken horizontal line indicates the depth of the major chemical gradient, the so-called chemocline.

in the probe (see Figure 1). The sound speed sensor provided a direct time of flight measurement over $10 \mathrm{~cm}$ from a transducer to a reflector table and back. As a backup, we also mounted a CTD probe "CTM102" (Sea and Sun Technology, Trappenkamp Germany; data were for backup but not used in this publication). The full instrument weighted $9.9 \mathrm{~kg}$; it was easy to handle and could be carried in a case on an airplane.

Measurements of EC showed the removal of the deep water from the monimolimnion (120-209 $\mathrm{m}$ depth) by syphoning water from close to the lake bed to the surface. As a consequence, the upper water body of constant salinity grew in thickness from ca. $100 \mathrm{~m}$ in 2014 to $120 \mathrm{~m}$ in 2016 (Figure 2). The rates of the gradient lowering agreed well with the expected value from the discharge through the degassing pipes (see Ohba et al., 2020). The higher salinity water at the surface induced mixing and created the water body of constant EC.

The temperature profile showed a shallow epilimnion of about $10 \mathrm{~m}$ thickness, below which we found an isothermal hypolimnion (Figure 2, see also Boehrer and Schultze 2008; Boehrer et al., 2013). Below $120 \mathrm{~m}$ depth, i.e., in the monimolimnion, temperature increased along with EC. The difference from 2014 could be explained by the continued drawdown by siphoning deeper water (Ohba et al., 2020). Temperatures in the hypolimnion had changed considerably from 2014. The deep recirculation before the measurements in March 2016 occurred at lower temperatures than in 2014, reaching the upper limit of the monimolimnion. This difference could explain the maintenance of the sharp temperature and EC gradients at the upper edge of the monimolimnion by erosive effects on the stratification (e.g., Boehrer et al., 2014).

Oxygen reached equilibrium with the atmosphere at the surface, but saturation values fell through the thermocline to remain relatively constant around $50 \%$ throughout the hypolimnion. The monimolimnion did not contain any dissolved oxygen. The $\mathrm{pH}$ was 6.5 in the hypolimnion, slightly higher in the epilimnion, while the monimolimnion $\mathrm{pH}$ showed acidic values around 5.5. The higher acidity was related to the presence of elevated concentrations of carbon dioxide, which dissociated in part into bicarbonate and hydronium ions.

Sound speed (time of flight measurements) followed the temperature through the thermocline above $10 \mathrm{~m}$. In the relatively homogeneous hypolimnetic water, sound speed increased at a quite constant rate to greater depth due to increasing hydrostatic pressure to finally increase even faster through the monimolimnion. There was a small but clearly visible difference between the profiles of 2016 and 2014. In the monimolimnion, this could be attributed to the drawdown (Ohba et al., 2020), including the effects of higher pressure at the deeper location in 2016, but in the hypolimnion the difference was mainly attributed to higher temperatures in 2014 .

\section{NEW APPROACH}

The profiles of temperature, EC, and pressure (depth) facilitated the calculation of sound speed $v_{U N E S C O}$ by implementation of the UNESCO formula. We followed the Saiki et al. (2017) convention and called the difference to measured sound speed $v_{\text {meas }}$ the "excess sound speed":

$$
\Delta v=v_{\text {meas }}-v_{U N E S C O}
$$

Carbon dioxide is the only dissolved substance present at high concentrations that does not contribute to EC. However, as dissolved carbon dioxide affects both density and adiabatic compressibility of water, it increases the sound speed as shown by Sanemasa et al. (2017). Hence we assumed that it is a measure for carbon dioxide. We first used the conversion factor $k_{1}=$ $0.0323-0.000523 \cdot T$ (with $\mathrm{T}$ in ${ }^{\circ} \mathrm{C}$ ) from Sanemasa et al. (2017) to calculate:

$$
c_{\mathrm{CO} 2}=\Delta v / k_{1}
$$

In a second step, the $\mathrm{pH}$ information was used to calculate bicarbonate concentration from 


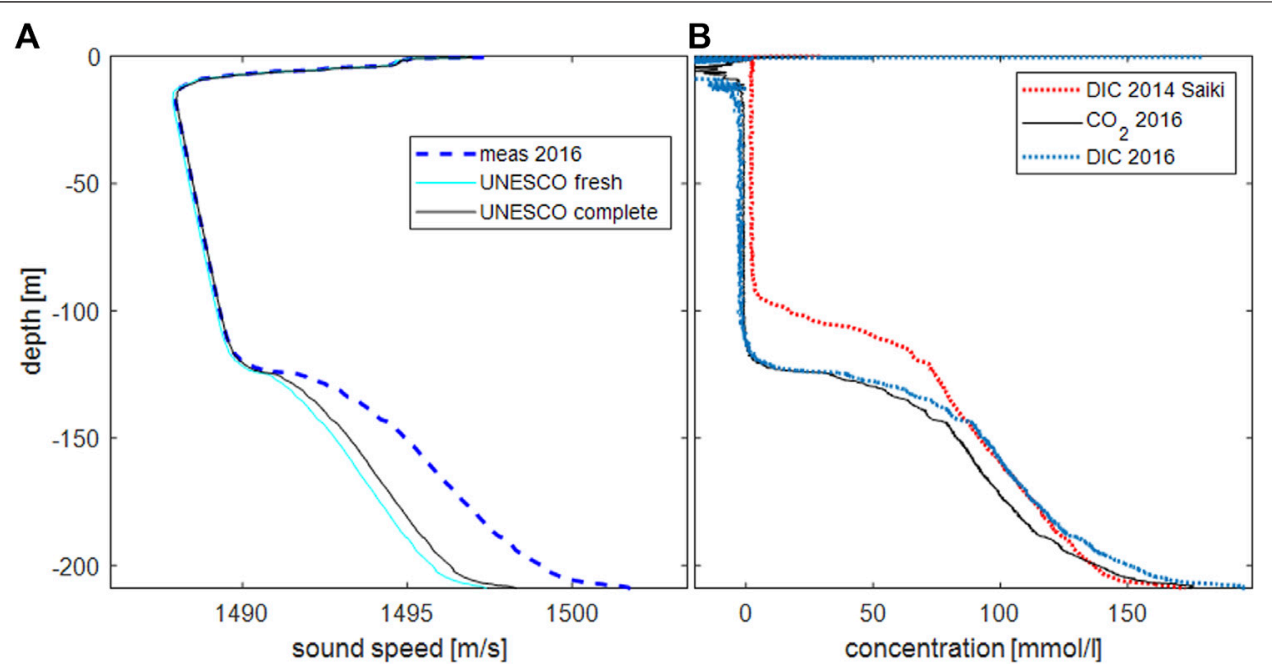

FIGURE 3 | (A): Sound speed as measured and calculated from temperature, electrical conductivity (either using measured values "UNESCO complete" or setting electrical conductivity to zero "UNESCO fresh") and pressure following UNESCO (Fofonoff, 1986). (B): profile of calculated carbon dioxide concentrations as derived from the sound speed excess.

TABLE 1 | Concentrations of solutes in Lake Nyos as reported by Kusakabe et al. (2008) (K) listed in Sanemasa et al. (2017) and by Anazawa et al. (2019) (A); n.a. = not available.

\begin{tabular}{|c|c|c|c|c|c|c|c|c|c|c|c|c|c|}
\hline & $\mathrm{Na}^{+}$ & $\mathbf{K}^{+}$ & $\mathrm{NH}_{4}{ }^{+}$ & $\mathbf{M g}^{2+}$ & $\mathrm{Ca}^{2+}$ & $\mathrm{Fe}^{2+}$ & $\mathrm{Mn}^{2+}$ & $\mathrm{SiO}_{2}$ & $\mathbf{C l}^{-}$ & $\mathrm{NO}_{3}{ }^{-}$ & $\mathrm{SO}_{4}{ }^{2-}$ & $\mathrm{HCO}_{3}{ }^{-}$ & Origin \\
\hline 2006/-195m & 0.94 & 0.15 & 0.60 & 3.78 & 1.58 & 2.37 & 0.036 & 1.29 & 0.028 & 0.035 & 0.028 & 17.1 & $\mathrm{mmol} / \mathrm{kg}(\mathrm{K})$ \\
\hline 2015/-207m & 0.81 & 0.18 & n.a. & 2.6 & 0.92 & 1.07 & 0.02 & n.a. & n.a. & n.a. & n.a. & n.a. & $\mathrm{mmol} / \mathrm{l}(\mathrm{A})$ \\
\hline 2016/-160m & 0.76 & 0.20 & 0.49 & 1.29 & 0.88 & 1.58 & 0.03 & 0.41 & 0.01 & 0.0 & 0.0 & 10.0 & $\mathrm{mmol} / \mathrm{l}$ (new data) \\
\hline
\end{tabular}

$$
c_{\mathrm{HCO} 3-}=K_{s} \frac{c_{\mathrm{CO} 2}}{c_{\mathrm{H}+}}=10^{p H-p K s} \cdot c_{\mathrm{CO} 2}
$$

where $\mathrm{pKs}=6.36$ (Worch, 2015), $\mathrm{pH}$ was taken from the multiparameter profile and $c_{\mathrm{CO} 2}$ from the calculation above (Eq. 2). The sum represented dissolved inorganic carbon (DIC):

$$
c_{\mathrm{DIC}}=c_{\mathrm{HCO} 3-}+c_{\mathrm{CO} 2}=\left(1+10^{p H-p K s}\right) \cdot c_{\mathrm{CO} 2}
$$

\section{RESULTS}

A comparison of the resulting DIC profile with the DIC profile published by Saiki et al. (2017) for 2014 showed the vertical shift due to the drawdown, but also the considerably higher concentrations (Figure 3B "2014 Saiki”).

Stability is controlled by density. Similar to sound speed, we capture the contribution of ionically dissolved substances by their contribution to EC. For quantification, we use the lambda-approach by Moreira et al. (2016) and Boehrer et al. (2010), who added the density contributions of solutes to the (potential) density of pure water. As in Schmid et al. (2003), we added the contribution of $\mathrm{CO}_{2}$ in a separate term:

$$
\rho\left(T, C_{25}\right)=\rho_{W}(T)+C_{25} \cdot\left(\lambda_{0}+\lambda_{1} \cdot\left(T-25^{\circ} \mathrm{C}\right)\right)+\gamma \cdot G \cdot c_{C O 2}
$$

with fractional density contribution $\gamma=0.212$ of $\mathrm{CO}_{2}$ from Dietz et al. (2012), and molar mass $\mathrm{G}=44.01 \mathrm{~g} / \mathrm{mol}$ of $\mathrm{CO}_{2}$. The coefficients $\lambda_{0}=0.77 \mathrm{~kg} / \mathrm{m}^{3} /(\mathrm{mS} / \mathrm{cm})( \pm 0.014)$ und $\lambda_{1}=$ $-0.0015 \mathrm{~kg} / \mathrm{m}^{3} / \mathrm{K} /(\mathrm{mS} / \mathrm{cm})( \pm 0.00005)$ were obtained from the Moreira et al. (2016) density calculator, by inserting the salt composition measured in 2016 at $160 \mathrm{~m}$ depth (Table 1).

To check the variability with composition, we also inserted the salt composition measured by Kusakabe et al. (2008) at a depth of $195 \mathrm{~m}$ as reported by Sanemasa et al. (2017) and Anazawa et al. (2019), where we closed the charge balance with bicarbonate. The results for $\lambda_{0}$ and $\lambda_{1}$ agreed for all three solute compositions within the given narrow bounds. As a consequence, the density formula for Lake Nyos can be considered quite robust and valid for the time period covered by observations. The value for $\lambda_{0}$ is large, i.e., formulae based on ocean water conditions would greatly under-estimate the density effect of solutes affecting EC. Inserting the measured and calculated values into Eq. 5 yielded the (potential) density profile (Figure 4), where we also showed the contribution of $\mathrm{CO}_{2}$ separately.

Gas pressure profiles are essential to judge the proximity to spontaneous gas exsolution (Kusakabe, 2017). Hence we calculated the gas pressure induced by carbon dioxide using 

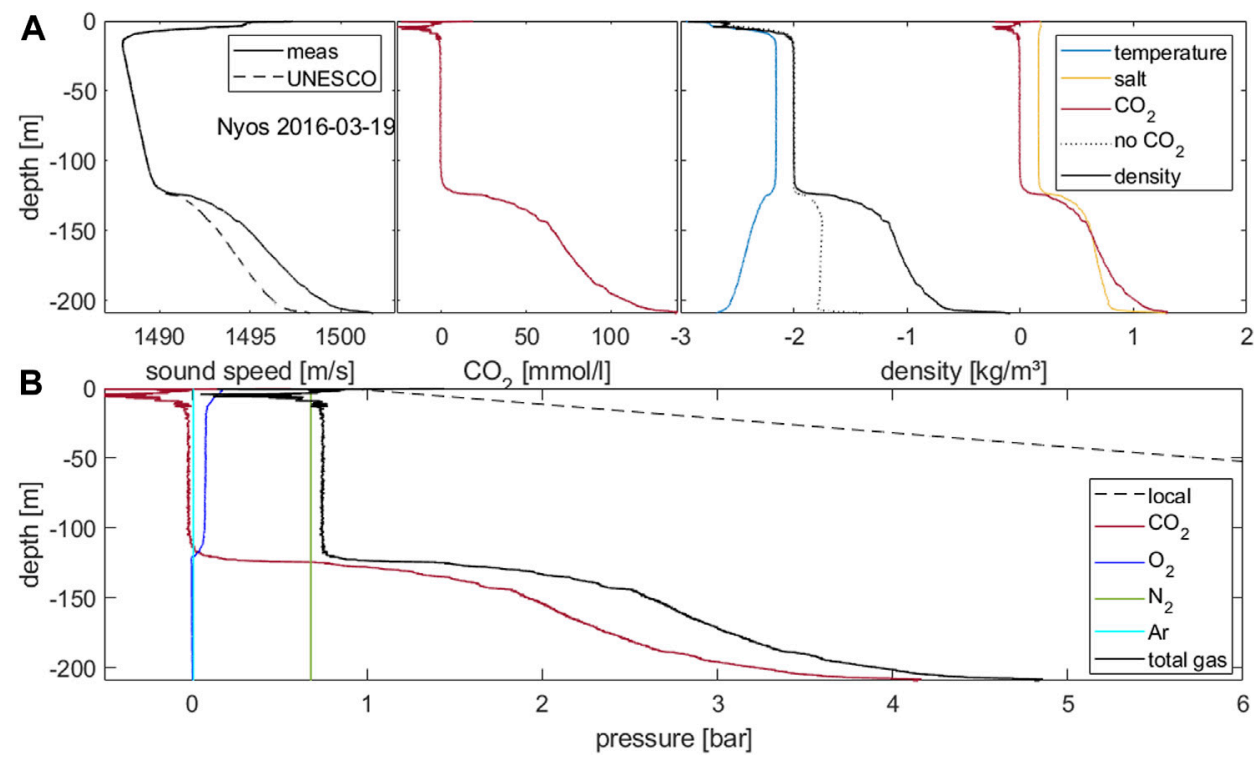

FIGURE 4 | (A): Sound speed as measured and calculated from temperature, electrical conductivity and pressure following UNESCO formula. Middle panel: profile of calculated carbon dioxide concentrations as derived from the sound speed excess. Right panel: (potential) density (-1,000 kg/m³) as calculated from measured temperature, EC and carbon dioxide concentration and the single contributions. (B): profiles of gas pressure calculated for the major contributing gases and total gas pressure as the sum in comparison to local pressure.

Henry's law and the temperature-dependent Henry coefficient. The values lie between 2 and 3 bars through the monimolimnion and rise approaching 4 bars close to the lake bed (Figure 4). In addition, we converted oxygen saturation into oxygen gas pressure, which started at about 0.2 bar at the surface (low atmospheric pressure at the altitude of $1,100 \mathrm{~m}$ a.s.l.), about 0.1 bar ( $50 \%$ saturation of atmospheric pressure at $1,100 \mathrm{~m}$ a.s.l.) throughout the hypolimnion and zero in the monimolimnion. Gas pressure for nitrogen was assumed to be in equilibrium with atmospheric $N_{2}$ partial pressure at the altitude of Lake Nyos, i.e., 0.68 bar. A similar procedure was implemented for argon (Ar) to yield 0.0087 bar. The contribution of vapour pressure reached less than 0.025 bar at temperatures measured in Lake Nyos $\left(22-24^{\circ} \mathrm{C}\right.$, Figure 2).

\section{DISCUSSION}

Our goal was to test whether commercially available equipment was suited for estimating dissolved carbon dioxide on the basis of the sound speed. We used the complete UNESCO equation (Fofonoff, 1986, including the temperature scale change in 1990) for sound speed from temperature, salinity (i.e., EC), and pressure. This formula connects physical quantities, such as density and sound speed, to accurately measurable quantities of electrical conductivity, temperature and pressure. The conversion is valid for the salt composition of ocean water and applicable to limnic waters with some loss of accuracy. Most oceanographic CTD probes supply this UNESCO sound speed as a derived quantity. We compared the calculated sound speed with the sound speed from directly measured time-of-flight to find the excess sound speed for estimating carbon dioxide concentration (Eqs 1, 2).

The inclusion of the salinity term in the UNESCO equation resulted in very good agreement between measured and calculated sound speeds at depths, where we did not expect high concentrations of $\mathrm{CO}_{2}$, i.e., in the hypolimnion between 10 and $120 \mathrm{~m}$ depth. In the temperature-stratified top layer, larger deviations in the range of a few $\mathrm{m} / \mathrm{s}$ were visible, which could be identified as artefacts and attributed to the different measuring volumes of sound speed $(10 \mathrm{~cm})$, temperature (as well as EC; more in the range of $2 \mathrm{~cm}$; see Figure 1) and the high vertical temperature gradients that pronounced this feature. Below $120 \mathrm{~m}$ depth, the differences between calculated and measured sound speed were indicative of increasing carbon dioxide concentrations up to about $150 \mathrm{mmol} / \mathrm{l}$ at the lake bed, in good agreement with expectations from earlier measurements.

In comparison with the 2014 data, the drawdown effect became clearly visible. The steep gradient of carbon dioxide was moved downward by about $20 \mathrm{~m}$ due to the degassing facility removing deep water from close to the lake bed. At depths between 140 and $180 \mathrm{~m}$, DIC concentrations in 2016 were marginally higher than in 2014; at depths below $180 \mathrm{~m}$, the difference was larger. This indicated additional DIC, which should be the case very close to the lake bed, but probably not in the depth range from 140 to $200 \mathrm{~m}$. It is more likely that this difference arose from the different approaches and different types of equipment that were implemented by the various research groups. We used the original coefficient $k_{1}$ form the laboratory measurement by Sanemasa et al. (2017), as the data from 2014 indicated a reasonably good agreement. In contrast, Saiki et al. (2017) saw evidence from samples that the correlation between 
DIC and sound speed excess required corrections, which they mainly attributed to the presence of bicarbonate. The measurements by Sanemasa et al. (2017) were done at smaller outside (hydrostatic) pressures, hence may not exactly reflect the situation at great depth in Lake Nyos. We did not have the capabilities to resolve this disagreement. A closer investigation of the correlation between dissolved carbon dioxide (as well as other dissolved substances) and sound speed would be desirable. This may be possible by additional laboratory experiments or application of this method to other gas-charged lakes.

We calculated dissolved bicarbonate from the dissociation product of carbonic acid. At a $\mathrm{pH}$ about 1 unit smaller than the pKs of 6.36, bicarbonate contributed about $10 \%$ to DIC; hence even a considerable error in the $\mathrm{pH}$ measurement would not heavily bias the DIC. In comparison to the calculated values from Saiki et al. (2017) approach, very small but visible differences appeared between 10 and $120 \mathrm{~m}$ depth (hypolimnion). The commercial probe showed good agreement between calculated and measured values (i.e., no $\mathrm{CO}_{2}$ in Figure 3B), most likely due to the inclusion of salinity in the calculation.

We implemented Eq. 5 to calculate a density profile. We used the formula by Tanaka et al. (2001) for density of pure water. We evaluated the density contribution of dissolved ions on the basis of the measured EC profile, and finally added the density contribution of the dissolved $\mathrm{CO}_{2}$. The increasing temperatures in the monimolimnion resulted in a density contribution which counteracted the stability, providing the potential for double diffusive convection (Schmid et al., 2004; Hirslund 2019). This was outbalanced by the dissolved solids, which contributed a density difference of about $0.5 \mathrm{~kg} / \mathrm{m}^{3}$, tantamount to the density effect of a $2^{\circ} \mathrm{C}$ temperature difference that the mixolimnion would need to be colder than the monimolimnion to overcome the density of the monimolimnion. The density contribution of the dissolved $\mathrm{CO}_{2}$ was considerably larger, i.e. about $0.7 \mathrm{~kg} / \mathrm{m}^{3}$. In conclusion, the major contribution that maintained the stable stratification came from the dissolved $\mathrm{CO}_{2}$. Together, all terms indicated a density difference of $1 \mathrm{~kg} / \mathrm{m}^{3}$ between waters above and below the major chemocline at $120 \mathrm{~m}$ depth. However as this mainly relied on the contribution of the volatile $\mathrm{CO}_{2}$, this could not be considered safe, and the degassing of the lake had to be completed until the remaining $\mathrm{CO}_{2}$ would not pose a danger.

From our results, gas pressures could be calculated by solving Henry's law. The contributions of $\mathrm{CO}_{2}$ (from sound speed), oxygen from sensor measurements, and vapour pressure from temperature could be calculated in a straightforward manner. For nitrogen and argon, we assumed equilibrium with the atmospheric pressure at the altitude of the surface of Lake Nyos. These calculations yielded a total gas pressure profile as the sum of these single terms. As shown in the paper by Bärenbold et al. (2019) for the extreme case of Lake Kivu, non-linearities were expected to be small (in the range of few percent). The total gas pressure is considerably smaller than the absolute (local) pressure. Hence spontaneous exsolution of $\mathrm{CO}_{2}$ would require that water be lifted from a depth of $140 \mathrm{~m}$ to about $15 \mathrm{~m}$ depth. This could only happen if the entire water column lost its stability, as described in the paragraph above on density.

\section{CONCLUSION}

The CTD and sound speed measurements in March 2016 at Lake Nyos, Cameroon, provided a data set that correlated very well with the $\mathrm{CO}_{2}$ concentrations observed along a vertical depth profile from earlier measurements. A commercial sound speed sensor attached to a high accuracy CTD probe was successfully tested for its suitability to survey carbon dioxide in Lake Nyos. The instrumentation can be easily transported to remote areas, such as Lake Nyos, to acquire vertical profiles at regular time intervals. Although this approach was not a direct measurement, the accumulation of carbon dioxide is manifested in detectable, increasing sound speed values, i.e., sound speed excess with respect to calculated sound speed based on EC, temperature and depth following the UNESCO formula. As a mitigation strategy, once sound speed measurements indicate carbon dioxide concentrations of concern, direct gas measurements and dissolved gas sampling campaigns could be implemented rapidly in order to confirm the elevated gas concentrations.

Finally, the measurements of CTD and sound speed relied only on physical quantities that could be measured at high accuracy, frequency and reproducibility. Although possibly more difficult to assess in terms of absolute accuracy, this method is particularly well-suited for documenting temporal evolution and quantifying changes much more rapidly and frequently compared to direct $\mathrm{CO}_{2}$ measurements. Profiles at high vertical resolution (decimetres) could be accomplished which guarantee that no layers remain undetected. In addition, vertical displacement, such as drawdown through siphoning, might be detectable on the base of the profile shape. Our measurements extend the documentation of the degassing progress by a further two years. We recommend frequent surveys using this approach for the timely detection of dangerous dissolved $\mathrm{CO}_{2}$ concentrations at Lake Nyos, as well as at other similarly hazardous lakes.

Extending the work of Saiki et al. (2017), we separated the effect of $\mathrm{CO}_{2}$ on sound speed from the bicarbonate contribution. This made the correlation factors independent of $\mathrm{pH}$ and background salinity. This was a step towards using the approach at other lakes with high $\mathrm{CO}_{2}$ (e.g., the episodically recharged Lago Albano, Italy). A further investigation of the quantitative connection between solutes and sound speed remains desirable.

\section{DATA AVAILABILITY STATEMENT}

The original contributions presented in the study are included in the article, further inquiries can be directed to the corresponding author.

\section{AUTHOR CONTRIBUTIONS}

BB was responsible for the measurements 2016, and he was the lead author of this contribution. KS and TO provided the 2014 data and the detailed numerical approach of 2014. GT, DR, and MK provided information on the geological setting, comparison with other volcanic lakes and the information about the degassing history. All authors were present at the 2016 meeting and/or field measurements in 2016. All were involved in writing this paper. 


\section{REFERENCES}

Anazawa, K., Fantong, W. Y., Ueda, A., Ozawa, A., Kusakabe, M., Yoshida, Y., et al. (2019). Environmental Modifications of Lake Nyos Surface Water by Artificial Degassing. J. Afr. Earth Sci. 152, 115-121. doi:10.1016/ j.jafrearsci.2019.02.009

Bärenbold, F., Boehrer, B., Grilli, R., Mugisha, A., von Tümpling, W., Umutoni, A., et al. (2020). No Increasing Risk of a Limnic Eruption at Lake Kivu: Intercomparison Study Reveals Gas Concentrations Close to Steady State. PLoS ONE 15 (8), e0237836. doi:10.1371/journal.pone.0237836

Boehrer, B., Yusta, I., Magin, K., and Sanchez-España, J. (2016). Quantifying, Assessing and Removing the Extreme Gas Load from Meromictic Guadiana Pit lake, Southwest Spain. Sci. Total Environ. 563-564, 468-477. doi:10.1016/ j.scitotenv.2016.04.12410.1016/j.scitotenv.2016.04.118

Boehrer, B., Herzsprung, P., Schultze, M., and Millero, F. J. (2010). Calculating Density of Water in Geochemical lake Stratification Models. Limnol. Oceanogr. Methods 8 (11), 567-574. doi:10.4319/lom.2010.8.0567

Boehrer, B., Jordan, S., Leng, P., Waldemer, C., Schwenk, C., Hupfer, M., et al. (2021). Gas Pressure Dynamics in Small to Mid-Size Lakes. Water 13 (13), 1824. doi:10.3390/w13131824

Boehrer, B., Kiwel, U., Rahn, K., and Schultze, M. (2014). Chemocline Erosion and its Conservation by Freshwater Introduction to Meromictic Salt Lakes. Limnologica 44, p 81-89. doi:10.1016/j.limno.2013.08.003

Boehrer, B., and Schultze, M. (2008). Stratification of Lakes. Rev. Geophys. 46 (2), RG2005. doi:10.1029/2006rg000210

Boehrer, B., von Rohden, C., and Schultze, M. (2013). "Physical Features of Meromictic Lakes: Stratification and Circulation," in Ecology of Meromictic Lakes. Editors R. D. Gulati, E. S. Zadereev, and A. G. Demergendzhi (Heidelberg: Springer), 61-86.

Boehrer, B., von Tümpling, W., Mugisha, A., Rogemont, C., and Umutoni, A. (2019). Reliable Reference for the Methane Concentrations in Lake Kivu at the Beginning of Industrial Exploitation. Hydrol. Earth Syst. Sci. 23, 4707-4716. doi:10.5194/hess-23-4707-2019

Cabassi, J., Tassi, F., Vaselli, O., Fiebig, J., Nocentini, M., Capecchiacci, F., et al. (2013). Biogeochemical Processes Involving Dissolved $\mathrm{CO}_{2}$ and $\mathrm{CH}_{4}$ at Albano, Averno, and Monticchio Meromictic Volcanic Lakes (Central-Southern Italy). Bull. Volcanol. 75, 683. doi:10.1007/s00445-012-0683-0

Caracausi, A., Nuccio, P. M., Favara, R., Nicolosi, M., and Paternoster, M. (2009). Gas hazard Assessment at the Monticchio Crater Lakes of Mt. Vulture, a Volcano in Southern Italy. Terra Nova 21, 83-87. doi:10.1111/j.1365-3121.2008.00858.x

Chiodini, G., Tassi, F., Caliro, S., Chiarabba, C., Vaselli, O., and Rouwet, D. (2012). Time-dependent $\mathrm{CO} 2$ Variations in Lake Albano Associated with Seismic Activity. Bull. Volcanol. 74, 861-871. doi:10.1007/s00445-011-0573-x

Dietz, S., Lessmann, D., and Boehrer, B. (2012). Contribution of Solutes to Density Stratification in a Meromictic lake (Waldsee/Germany). Mine Water Environ. 31 (2), 129-137. doi:10.1007/s10230-012-0179-3

Fofonoff, N. P. (1986). Physical Properties of Seawater: A New Salinity Scale and Equation of State for Seawater. J. Geophys. Res. 90 (C2), 3332-3342.

Halbwachs, M., Sabroux, J.-C., and Kayser, G. (2020). Final Step of the 32-year Lake Nyos Degassing Adventure: Natural CO2 Recharge Is to Be Balanced by Discharge through the Degassing Pipes. J. Afr. Earth Sci. 167, 103575. doi:10.1016/j.jafrearsci.2019.103575

Hirslund, F. (2019). Dynamics of Diffusive Layering and Chemocline Formation in Lake Kivu and Brine Pools. J. Afr. Earth Sci. 159, 103520. doi:10.1016/ j.jafrearsci.2019.103520

Horn, C., Metzler, P., Ullrich, K., Koschorreck, M., and Boehrer, B. (2017). Methane Storage and Ebullition in Monimolimnetic Waters of Polluted Mine Pit lake Vollert-Sued, Germany. Sci. Total Environ. 584-585, 1-10. doi:10.1016/j.scitotenv.2017.01.151

Kling, G. W., Clark, M. A., Wagner, G. N., Compton, H. R., Humphrey, A. M., Devine, J. D., et al. (1987). The 1986 Lake Nyos Gas Disaster in Cameroon, West Africa. Science 236 (4798), 169-175. doi:10.1126/science.236.4798.169
Kusakabe, M. (2017). Lakes Nyos and Monoun Gas Disasters (Cameroon)Limnic Eruptions Caused by Excessive Accumulation of Magmatic $\mathrm{CO} 2$ in Crater Lakes. Geochem. Monogr. Ser. 1 (1), 1-50. doi:10.5047/ gems.2017.00101.0001

Kusakabe, M., Ohba, T., Issa, Y., Yoshida, H., Ohizumi, T., Evans, W. C., et al. (2008). Evolution of CO2 in Lakes Monoun and Nyos, Cameroon, before and during Controlled Degassing. Geochem. J. 42, 93-118. doi:10.2343/ geochemj.42.93

Kusakabe, M., Tiodjio, R. E., Christenson, B., Saiki, K., Ohba, T., and Yaguchi, M. (2019). Enrichment of Ferrous Iron in the Bottom Water of Lake Nyos. J. Afric Earth Sci. 37-46. doi:10.1016/j.jafrearsci.2018.10.014

Lorke, A., Tietze, K., Halbwachs, M., and Wüest, A. (2004). Response of Lake Kivu Stratification to Lava Inflow and Climate Warming. Limnol. Oceanogr. 49 (3), 778-783. doi:10.4319/lo.2004.49.3.0778

Moreira, S., Schultze, M., Rahn, K., and Boehrer, B. (2016). A Practical Approach to lake Water Density from Electrical Conductivity and Temperature. Hydrol. Earth Syst. Sci. 20, 2975-2986. doi:10.5194/hess-20-2975-2016

Ohba, T., Ooki, S., Oginuma, Y., Yoshida, H., Ntchantcho, R., Ako, A., et al. (2020). Temperature and Electrical Conductivity of Water in Lake Nyos Transmitted by an Automatic Observation Buoy. J. Afr. Earth Sci. 172, 103976. doi:10.1016/ j.jafrearsci.2020.103976

Rouwet, D., Chiodini, G., Ciuccarelli, C., Comastri, A., and Costa, A. (2019). Lago Albano, the "Anti-nyos-type" lake: The Past as a Key for the Future. J. Afr. Earth Sci. 150, 425-440. doi:10.1016/ j.jafrearsci.2018.09.019

Rouwet, D., Tamburello, G., Chiodini, G., Pecoraino, G., Procesi, M., Ricci, T., et al. (2021). New Insights into the Degassing Dynamics of Lago Albano (Colli Albani Volcano, Rome, Italy) during the Last Three Decades (1989-2019). Ijg 140 (1), 29-41. doi:10.3301/IJG.2020.19

Rouwet, D. (2021). "Volcanic lake Dynamics and Related Hazards," in Forecasting and Planning for Volcanic Hazards, Risks and Disasters, 439-471. doi:10.1016/ b978-0-12-818082-2.00011-1

Saiki, K., Kaneko, K., Ohba, T., Sanemasa, M., Kusakabe, M., Ntchantcho, R., et al. (2017). "Vertical Distribution of Dissolved CO2 in Lakes Nyos and Monoun (Cameroon) as Estimated by Sound Speed in Water," in Geochemistry and Geophysics of Active Volcanic Lakes. Editors T. Ohba, B. Capaccioni, and C. Caudron (London: Geological Society), 437, 185-192. Special Publications. doi:10.1144/sp437.10

Sánchez-España, J., Boehrer, B., and Yusta, I. (2014). Extreme Carbon Dioxide Concentrations in Acidic Pit Lakes Provoked by Water/rock Interaction. Environ. Sci. Technol. 48 (8), 4273-4281. doi:10.1021/ es5006797

Sánchez-España, J., Yusta, I., and Boehrer, B. (2020). Degassing Pit Lakes: Technical Issues and Lessons Learnt from the HERCO2 Project in the Guadiana Open Pit (Herrerías Mine, SW Spain). Mine Water Environ. 39, 517-534. doi:10.1007/s10230-020-00654-1

Sanemasa, M., SaikiKaneko, K. K., Kaneko, K., Ohba, T., Kusakabe, M., Ntchantcho, R., et al. (2017). "A New Method to Determine Dissolved CO2 Concentration of Lakes Nyos and Monoun Using the Sound Speed and Electrical Conductivity of lake Water," in Geochemistry and Geophysics of Active Volcanic Lakes. Editors T. Ohba, B. Capaccioni, and C. Caudron (London: Geological Society), 437, 193-203. Special Publications. doi: $10.1144 / S P 437.5$

Schmid, M., Halbwachs, M., Wehrli, B., and Wüest, A. (2005). Weak Mixing in Lake Kivu: New Insights Indicate Increasing Risk of Uncontrolled Gas Eruption. Geochem. Geophys. Geosyst. 6, a-n. doi:10.1029/2004GC000892

Schmid, M., Lorke, A., Dinkel, C., Tanyileke, G., and Wüest, A. (2004). Doublediffusive Convection in Lake Nyos, Cameroon. Deep Sea Res. Oceanographic Res. Pap. 51, 1097-1111. doi:10.1016/j.dsr.2004.02.010

Schmid, M., Lorke, A., Wüest, A., Halbwachs, M., and Tanyileke, G. (2003). Development and Sensitivity Analysis of a Model for Assessing Stratification and Safety of Lake Nyos during Artificial Degassing. Ocean Dyn. 53, 288-301. doi:10.1007/s10236-003-0032-0 
Sigurdsson, H., Devine, J. D., Tchoua, F. M., Presser, T. S., Pringle, M. K. W., and Evans, W. C. (1987). Origin of the Lethal Gas Burst from Lake Monoun. Cameroun. J. Volcanol. Geotherm. Res. 31 (1-2), 1-16. doi:10.1016/03770273(87)90002-3

Tanyileke, G., Ntchantcho, R., Fantong, W. Y., Aka, F. T., and Hell, J. V. (2019). 30 Years of the Lakes Nyos and Monoun Gas Disasters: A Scientific, Technological, Institutional and Social Adventure. J. Afr. Earth Sci. 150, 415-424. doi:10.1016/j.jafrearsci.2018.11.022

Worch, E. (2015). Hydrochemistry. Berlin/Boston: deGruyter.

Conflict of Interest: The authors declare that the research was conducted in the absence of any commercial or financial relationships that could be construed as a potential conflict of interest.
Publisher's Note: All claims expressed in this article are solely those of the authors and do not necessarily represent those of their affiliated organizations, or those of the publisher, the editors and the reviewers. Any product that may be evaluated in this article, or claim that may be made by its manufacturer, is not guaranteed or endorsed by the publisher.

Copyright $\odot 2021$ Boehrer, Saiki, Ohba, Tanyileke, Rouwet and Kusakabe. This is an open-access article distributed under the terms of the Creative Commons Attribution License (CC BY). The use, distribution or reproduction in other forums is permitted, provided the original author(s) and the copyright owner(s) are credited and that the original publication in this journal is cited, in accordance with accepted academic practice. No use, distribution or reproduction is permitted which does not comply with these terms. 